\title{
Electric Vehicles - An Introduction of the Tesla for Strategy and Leadership
}

\author{
S. Gayathri, D. Anitha Kumari
}

\begin{abstract}
The need for sustainable growth is felt now than ever before because of various disasters and catastrophes due to unplanned human activity. The dwindling fossil fuels are a major issue and various alternate sources of energy are sought by companies. The $E$ vehicle is an emerging concept and the automobile industry is conducting extensive research to make the option feasible and commercially viable. There are already some first movers like Tesla who have successfully developed their model and moving forward. This paper analyses the strategy and leadership of Tesla which have enabled them to be take the first mover advantage. A descriptive research based on secondary data had been employed in this study.
\end{abstract}

Keywords : E vehicles, Sustainability, Strategy, Market, Viability

\section{INTRODUCTION}

The depletion of fossil fuels and the awareness towards sustainability had made many countries to opt for cleaner fuels. We find that the Government of India, in this regard, had set a 2030 target to migrate completely to electric vehicles. There are lot of questions about the feasibility of this target and the available supporting eco system for this transition. The passenger vehicle segment is yet to upgrade to this technology in India, except for a few players like Mahindra\& Mahindra, who manufactures and sells electric cars. This study had analysed the case of Tesla in the light of their approach towards technology, scalability and leadership style.

\section{RESEARCH METHODOLOGY}

Case study is the most preferred approach when an intensive investigation is carried out on a specific issue. This study had focused on the leadership strategies and unique skill sets of Elon Musk. This study had given an overview on the leadership style by Elon Musk in the disruptive era. When the technological changes are quite fast paced, a dynamic workforce, skilled in the latest technology and a more dynamic leadership is needed.

Revised Version Manuscript Received on August 19, 2019.

Dr.S.Gayathri, Associate Professor, Department of Management Studies, Vels Institute of Science, Technology\& Advanced Studies (VISTAS), Pallavaram, Chennai,TamilNadu, India

(Email: : gayathri.sms@ velsuniv.ac.in)

Dr. D. AnithaKumari, Associate Professor, Department of Management Studies, Vels Institute of Science, Technology\& Advanced Studies (VISTAS), Pallavaram, Chennai, TamilNadu, India

(Email: : anitha.sms@velsuniv.ac.in)

\section{DISRUPTIVE TECHNOLOGY}

Tellis (2006) in his article had clearly summarized the Disruptive Technology of Christensen's (1997) thesis. The main findings of the summary are as follows:

(1) Any new technology would underperform the existing technology which is dominant and wide prevalent and the regular mass customers would not be interested

(2) Products made out of disruptive technologies are considerably cheap, easy to use .

(3) Disruptive technology is commercialised first in the insignificant market. So Incumbents usually do not consider it a rational decision to invest in the disruptive market.

(4) The new disruptive technology slowly gains the confidence of the users, meets the required standards of the mainstream market.

(5) There is a certain point when the new disruptive technology becomes widely prevalent and replaces the mainstream market.

Disruptive technologies do not promise immediate success and takes it own time for acceptance in the market. The emphasis here is on the role of leaders who stumble at various stages of the disruption and how transformational styles have made the journey easier. Musk is clear on the game plan of the disruptive technology. While doing above, also provide zero emission electric power generation options

\section{LEADERSHIP IN THE DISRUPTIVE ERA}

The changes taking place in the current industry scenario is fast paced and there are frequent technology shifts. There is a need to keep abreast with the changes failing which the organisation might lose its market. The present leaders have the responsibility of leading their workforce towards the change in the most effective way. Crawford (2005) had emphasised the need for transformational leadership for the organisation in knowledge management. He had emphasised that transformational leaders were much effective in managing the dexterities of technology in the changing landscape of workspace and its demands. In this aspect, Elon Musk had proved himself to be the greatest influencer for the company with his strong technical background and unflinching vision for the company. It is not only the industry that has undergone change but also the workforce, its diversity, technology, pace of change and knowledge updation methods. The shift from the industry era to the knowledge era has now compelled leaders to change their styles. The leaders of today need to be dynamic, adaptive and

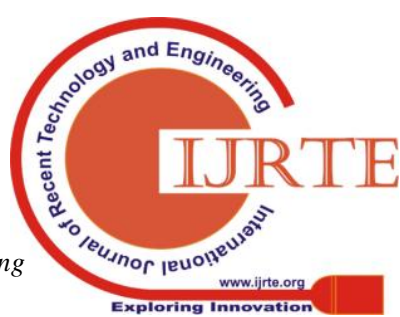


interactive as the new technologies are volatile and it needs a great acumen of predictability to lead the change.

\section{LEADERSHIP STYLE OF ELON MUSK}

Uhl-Bien (2007) in their research had proposed the Complexity leadership theory in their research. Conventional leadership styles help in motivating the employees and improving the performance, but they often tend to affect the innovation front of the employees. The new model of Complexity leadership theory takes leadership to the next level, past the managerial functions. The leadership requirements of knowledge era are entirely different and this could be met by changing styles as per the needs of the organization.

Though there are mixed opinions about Elon Musk's role in Tesla, it could not be denied that he is the visionary who made the dream of commercialising electric vehicles into reality. So this research is on the leadership style of Musk and the prevailing industry analysis.. As Marshall (2011) emphasise, the visionary people move from one mistake to another with glee, as they would discover new things on their way. Elon musk enabled the automobile industry into increased sustainability through his battery technology.

In the view of Bass, , the transformational leader inspire and intellectually stimulate their employees than the conventional leaders who emphasize on the normal practices.(1999) Tesla had the spirit of innovation right from its genesis. Elon Musk comes up with new challenges and motivates the employees to question the conventional practices. Managers, who bring in change and manage it effectively, always influence the culture. (Alvesson,M., \&Sveningsson,S. 2015).

Tesla is part of the changing technological space that is agile and could easily accommodate changes in all fronts. The employees have imbibed the effects of disruption and the need for the agility with which they have to work. There had been instances where teams would work on a specific technology meticulously and the project would be discarded by Musk, based on his strategic contexts. The employees are prepared for this level of change and they are capable of embracing seamless change. The transformational style of Musk had been very suitable for bringing in a revolution in the industry.

Musk had a rough ride after he took position in the company. He was very keen on implementing the electric vehicle technology on a large scale and aspired towards it. As a transformational leader, his ideas percolated to his employees and they were ready to be the change agents. Though the company, initially came up with Roadster, an electric sports cover, they had the vision to manufacture electric passenger cars.

Musk and his team, completely understood that a revolution on a large scale cannot be done by a single company. If Tesla manufactures electric vehicles in large The availability of charging stations and low cost batteries were their major challenges. The award winning Tesla Model $S$ resulted in huge success. The technology patents of Tesla were made open source to disseminate the knowledge in the industry. He revolutionised the industry by the supercharger stations so that the industry is not hampered by the dearth of scale, they should enable the entire industry to transform.

charging stations. The mission of Tesla was "to accelerate the world's transition to sustainable transport." Musk had inspired the change and now the mission is "to accelerate the world's transition to sustainable energy".

Pricing is one important factor in commercialising any innovation. Electric cars, are high priced as it is an new technology. There are limited suppliers and technology ennablers in this stage. The experience curve benefits are less realised during this phase. Tesla had made a good profit through its model $\mathrm{S}$. The learning from model $\mathrm{S}$, has definitely led to improvements in Model 3.

Organisational culture is always shaped and strengthened by the leader, his commitment and his messages,Klein and Wallis(2013). Musk had always made his employees to reach the unimaginable goals. Even trivial matters are innovated and speeded up here. A good example, is how they a transported huge stamping presses in a period of four months, that usually requires a year. The relentless pursuit for innovation had enabled the Tesla employees to forge an innovative culture, where they work towards the target, defying time.

Tesla had become the common name for electrification. Port Liner, a dutch company, is going to introduce autonomous, electric barges for the European market and they have dubbed it as "Tesla Ships". Such is the popularity and the brand impact of the electric car company. Musk inspires change and had influenced his employees, in a transformational way.(Alvesson, M., \&Sveningsson, S,2015)

\section{THE BLUE OCEAN STRATEGY\& RESULTS}

When the automobile industry was at cross roads, with the need to transform to electric power, there are some few first movers who had already experimented the Electric vehicle technology and succeeded. Blue oceans are defined by untapped market demand, unknown market space, high profit growth at low risk and Industries not in existence today. While the existing companies were contesting over the fossil fuel space, Tesla embraced the blue ocean through its electric vehicle. Scope exists for in depth analysis of this factors in to the Tesla case.

\section{Figure 1 \\ Red Ocean Vs Blue Ocean strategy (Kim \&Mauborgne, 2015.)}

\section{Red Ocean Strategy VS Blue Ocean Strategy}
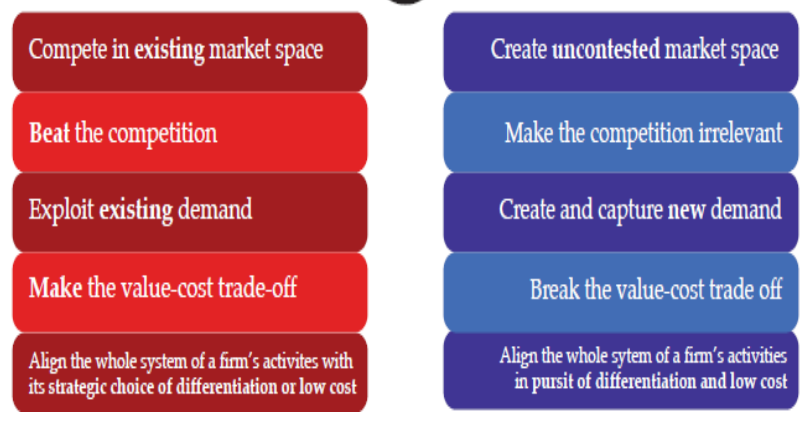

Published By: 
Tesla , by its model of electric cars, had created a less contested market space where the existing players are yet to enter. The competition in the conventional hydrocarbon system is irrelevant as it focuses on the new wave of electric vehicles. This has created awareness among the customers and demand for electric car is increasing. The activities of the company are in pursuit of this and through its battery technology; it is enabling the entire industry to shift towards the battery cars.

\section{CONCLUSION}

Economic moat is a competitive advantage that protects a business against challengers. Warren Buffet had contributed this term and he is a firm believer in the concept of moats and his investing philosophy relies on it. Musk in one of his tweets, made clear that moats alone will not help in sustaining the competitive advantage, but the pace of innovation is the most determining factor of competitiveness. He had in fact quipped that moats are lame without innovation. His transformational leadership and pace of innovation has helped Tesla in achieving the present position and there is still in hold from the innovator, in terms of products and an entire supported industry.

\section{REFERENCES}

1. Alvesson, M., \&Sveningsson, S. (2015). Changing organizational culture: Cultural change work in progress. London, Routledge, pp.120

2. Bass M. (1990): From transactional to transformation leadership: learning to share the vision. Journal, Organizational dynamic, 18(3), pp.19

3. Christensen, Clayton M. (1997). The Innovator's Dilemma: When New Technologies Cause Great Firms to Fail. Boston: Harvard Business School Press.

4. Crawford, C. B. (2005). Effects of transformational leadership and organizational position on knowledge management. Journal of knowledge management, 9(6), 6-16.

5. Jeck Welch,(2001) Straight from the Gut, Warner Business Books, str. 267

6. Marshall, E. S. (2011). Transformational Leadership in Nursing: From Expert Clinician to Influential Leader. New York: Springer Publishing Company, pp. 2-6.

7. Pandit, D., Joshi, M. P., Sahay, A., \& Gupta, R. K. (2018). Disruptive innovation and dynamic capabilities in emerging economies: Evidence from the Indian automotive sector. Technological Forecasting and Social Change, 129, 323-329.

8. Tellis, G. J. (2006). Disruptive technology or visionary leadership?. Journal of Product Innovation Management, 23(1), 34-38.

9. Uhl-Bien, M., Marion, R., \&McKelvey, B. (2007). Complexity leadership theory: Shifting leadership from the industrial age to the knowledge era. The leadership quarterly, 18(4), 298-318. 